\title{
Use of real time continuous glucose monitoring and intravenous insulin in type I diabetic mothers to prevent respiratory distress and hypoglycaemia in infants
}

\author{
Dario Iafusco*1, Fabrizio Stoppoloni ${ }^{\dagger 2}$, Gennaro Salvia ${ }^{\dagger 3}$, \\ Gilberto Vernetti ${ }^{\dagger 2}$, Patrizia Passaro ${ }^{\dagger 1}$, Goran Petrovski ${ }^{\dagger 4}$ and \\ Francesco Prisco ${ }^{\dagger 1}$
}

\begin{abstract}
Address: ${ }^{1}$ Department of Paediatrics, Second University of Naples, Italy, ${ }^{2}$ Maternal-Fetal Medicine Unit, Buon Consiglio Fatebenefratelli Hospital, Naples, Italy, ${ }^{3}$ Neonatology and N.I.C.U. , Buon Consiglio Fatebenefratelli Hospital, Naples, Italy and ${ }^{4}$ Clinic of Endocrinology and Diabetes, Skopje, Former Yugoslav Republic of Macedonia

Email: Dario Iafusco* - dario.iafusco@unina2.it; Fabrizio Stoppoloni - fabriziostoppoloni@libero.it; Gennaro Salvia - salvia@unina.it; Gilberto Vernetti - giovanna.tortorella@fastwebnet.it; Patrizia Passaro - patrigrant@tiscali.it; Goran Petrovski - goranp@endocrinology.org.mk; Francesco Prisco - francesco.prisco@unina2.it

* Corresponding author †Equal contributors
\end{abstract}

Published: I July 2008

BMC Pregnancy and Childbirth 2008, 8:23 doi:10.1 I86/I47I-2393-8-23

This article is available from: http://www.biomedcentral.com/I47I-2393/8/23

(C) 2008 lafusco et al; licensee BioMed Central Ltd.

This is an Open Access article distributed under the terms of the Creative Commons Attribution License (http://creativecommons.org/licenses/by/2.0), which permits unrestricted use, distribution, and reproduction in any medium, provided the original work is properly cited.
Received: 15 January 2008

Accepted: I July 2008

\begin{abstract}
Background: Pregnancy in Type I diabetic patients is a precarious condition, both for mother and fetus with increased the risk of prematurity and, immediately after delivery with risk of respiratory distress syndrome and hypoglycaemia in newborns. A strict control and monitoring of diabetes throughout pregnancy is important in reducing the impact of the disease on the fetus and newborn. In recent years many new technologies have been introduced to ameliorate diabetes monitoring, where the last is the Real-time Continuous Glucose Monitoring System (RT-CGMS).
\end{abstract}

Methods: In the last three years, $72 \mathrm{~h}$ continuous glucose monitoring system (RT-CGMS) (Medtronic, CA) was performed in 18 pregnant women with Type I diabetes in two moments of pregnancy: during treatment with betamethasone to prevent respiratory distress and during delivery. In both cases insulin was administered intravenous and the dose was changed on the basis of glycaemia.

Results: The results present the use of this new technique during two topics moments of pregnancy of type I diabetes patients when is very important intensively to monitor diabetes and to obtain the well being of the fetus. No infant experimented hypoglycaemia or respiratory distress syndrome at the moment and in the first hours after the birth.

Conclusion: We wish to stress the importance reducing glycaemia during administration of betamethasone and during labor. It is conceivable that the scarce attention paid to monitoring glucose levels in diabetic mothers during labor in gynaecological world may be due to the difficulty in glucose monitoring with the devices until now available. Hopefully, our anecdotal account may prompt improvements with RT-CGMS, and may lead to a better approach to the problem, thereby changing the prognosis of infants born to diabetic mothers. 


\section{Background}

Infants born to type 1 diabetic mothers are at significantly greater risk for perinatal morbidity. Two conditions are very frequent at the birth: respiratory distress syndrome (RDS) and hypoglycaemia. Strict maternal glycemic control during pregnancy complicated by diabetes mellitus reduces neonatal morbidity and mortality.

\section{Respiratory Distress Syndrome}

Infants of type 1 diabetic mothers are more likely to have respiratory symptoms in the newborn period from either RDS (surfactant deficiency) or retained fetal lung fluid (transient tachypnea of the newborn) after operative delivery.[1]. RDS occurs more frequently in IDMs (Infants of Diabetic Mother) because of later onset of maturity of the type II alveolar cells[2] and is secondary to pulmonary surfactant deficiency. Fetal hyperinsulinism is a key factor in the pathogenesis of RDS because insulin is believed to antagonize the physiological maturing effect of cortisol. [3]. Hyperinsulinism is also responsible for polycythemia, a condition inducing persistent pulmonary hypertension which complicates the course of RDS.

Ideally, RDS is prevented by excellent maternal glycemic control during pregnancy [2]. Corticosteroids are strongly recommended to prevent prematurity complications in newborns of non-diabetic mothers in whom a rise in blood glucose levels in the two days following administration of betamethasone has been reported [4]. Due to the higher risk of RDS in infants from diabetic mothers administration of betamethasone to the mother is even more advisable then in non-diabetic mothers. On the other side the consequent rise in blood glucose levels [4] is expected to be more marked in diabetic than in nondiabetic mothers thus requiring a strict adjustment of the insulin therapy. This because the fetal hyperinsulinism consequent to the maternal hyperglycemic peak could block the beneficial effect of the administered betamethasone on fetal pulmonary maturation.

\section{Hypoglycaemia}

In the diabetic pregnant the stress during the labour usually induces a further increase of blood glucose levels with a consequent rise of the fetal production of insulin and increased risk of hypoglycemia. Therefore, a close monitoring of blood glucose in the mother together with an appropriate insulin treatment during the last hours before delivery are needed.

Over the past years practitioners have sought to improve the outcome of diabetic pregnancies. In pregnancies complicated by type 1 diabetes, where excellent glucose control is desired to improve maternal and fetal outcomes, RT-CGMS, a novel well tolerated tool to assess 24-h glucose fluctuations, may have a role in fine-tuning manage- ment [5]. Its role may be crucial in two topic moments of pregnancy such as betamethasone therapy and labor.

\section{Methods}

Eighteen pregnant women (mean age $23.4 \pm 2.5$ yrs; range 18-28 yrs) with type 1 diabetes (mean age at the diagnosis $8.5 \pm 3.3$ yrs; mean duration of the disease $14.8 \pm 2.9$ yrs) were consecutively enrolled in the study in the last 3 years (2004-2007).

The research plan has been approved by the Ethics Committee of Department of Pediatrics of the Second University of Naples. An informed consent was signed by all mothers taking part to the study.

All patients wore Real Time Continuous Glucose Monitoring System sensors (RT-CGMS), in two moments: during treatment with betamethasone and in the perinatal period and during labor. The glycemic profile was obtained with a continuous glucose monitoring system, not equipped for real-time visualization of the results (CGMS Medtronic), in the first 4 patients at the beginning of the study and with a Guardian ${ }^{\circledR}$ Real Time CGMS (Medtronic) equipped for real-time visualization of the results in the others.

The CGMS unit consists of a glucose sensor, which is inserted into the subcutaneous tissue of the body and left in place for up to 72 hours. This sensor senses the interstitial fluid glucose levels electrochemically every $10 \mathrm{sec}$ onds, records an average value every 5 minutes and gives 288 values per day. The sensor of CGMS after 72 hours is removed and the data from the monitor are downloaded into a PC, which gives a continuous graph of the glucose values of the previous 3 days; Guardian ${ }^{\circledR}$ Real Time CGMS (Medtronic) uses a continuous telemetry display of realtime glucose values.

The RT-CGMS is an accurate tool for additional glucose monitoring in pregnant women with type 1 diabetes mellitus as previously demonstrated [6].

Betamethasone was administered intramuscularly (12 $\mathrm{mg} / 24 \mathrm{~h}$ for two days) between the $30^{\text {th }}$ and $32^{\text {nd }}$ week of gestation.

Continuous intravenous infusion of insulin (between $0.02 \mathrm{U} / \mathrm{kg} / \mathrm{h}$ and $0.06 \mathrm{U} / \mathrm{kg} / \mathrm{h}$ ), guided by glucose levels, enabled us to reach and maintain glucose levels constant between 100 and $150 \mathrm{mg} / \mathrm{dl}$ during treatment with betamethasone and during labor up to delivery in the vaginal delivery and between 80 and $100 \mathrm{mg} / \mathrm{dl}$ during the caesarean section birth. 

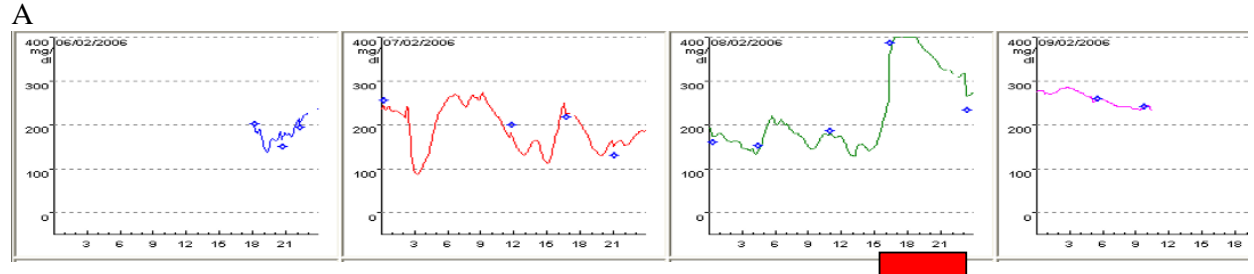

DM Stefania age 25 years, vaginal delivery, duration of gestation 32 weeks.

Infant birth weight $\mathrm{kg} 1.620\left(50^{\circ} \mathrm{pc}\right)$, glycaemia at birth $56 \mathrm{mg} / \mathrm{dl}$. No hypoglycaemic episodes during the first $72 \mathrm{hrs}$ after birth

B

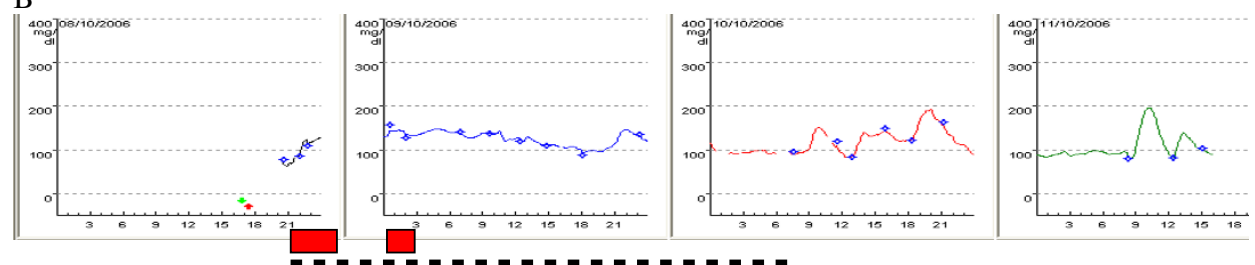

P Patrizia age 28 years, vaginal delivery, duration of gestation 38 weeks

Infant birth weight $\mathrm{kg} 4.100\left(97^{\circ} \mathrm{pc}\right)$, glycaemia at the birth $53 \mathrm{mg} / \mathrm{dl}$.

No hypoglycaemic episodes during the first $72 \mathrm{hrs}$ after birth

C
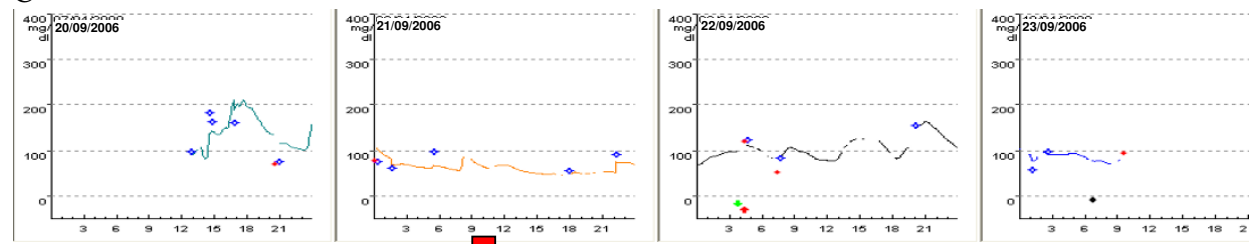

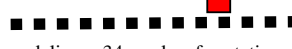

DM Daniela age 28 yrs caesarean delivery 34 weeks of gestation

Infant birth weight $\mathrm{kg} 3.520\left(97^{\circ} \mathrm{pc}\right)$, glycaemia at the birth $50 \mathrm{mg} / \mathrm{dl}$.

No hypoglycaemic episodes during the first 72 hrs after birth

D
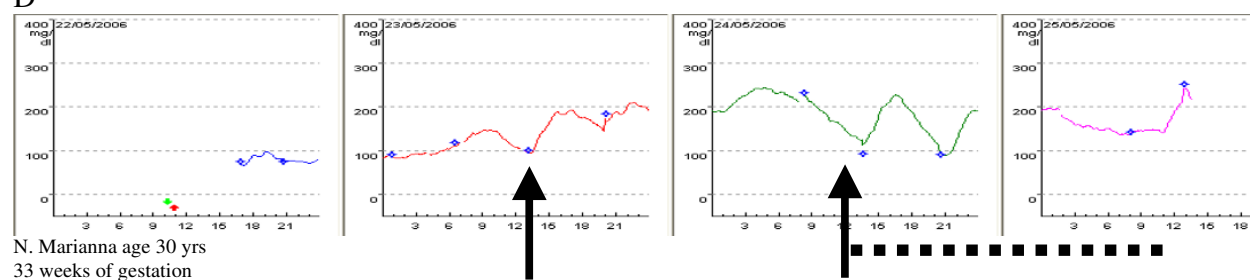

E

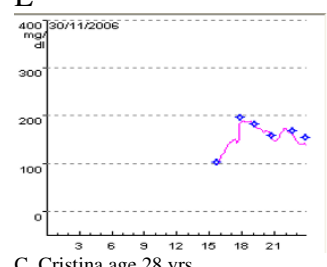

C. Cristina age 28 yrs

Figure legend

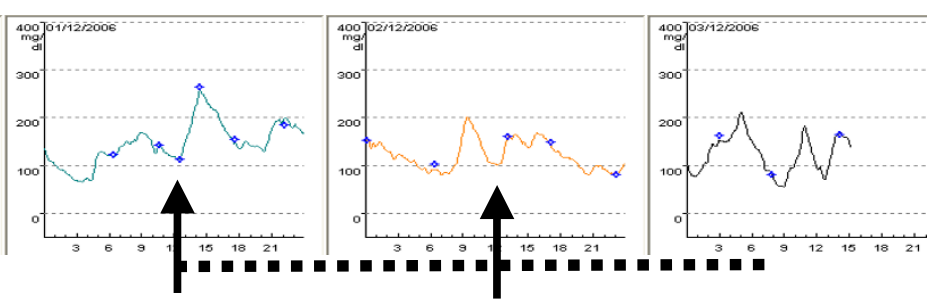

.

Labor $\square$ Insulin i.v. - - Betamethasone $12 \mathrm{mg}$ i.m. $\mathbf{A}$

On the $x$-axis are hours and every graph is a day. On the $y$-axis are glycemic values (mg/dl)

${ }^{\circ}$ The circle symbols represent glycaemia at the finger.

\section{Figure I}

Continuous Graph of the glucose values of 3 days. 


\section{Results and Discussion}

At the beginning of the study after betamethasone administration we tried to maintain the multi-injection insulin therapy but it did not prevent an increase of glycaemia despite of the increasing insulin dose.

Fig 1D shows the continuous graph of the glucose values of a patient who received, the day after betamethasone, multi-injection insulin therapy at a dose of 0,9 Units/Kg/ day in 4 administrations/day, which did not prevent an increase of glycaemia monitored for about $24 \mathrm{~h}$ (around $200 \mathrm{mg} / \mathrm{dl}$ with a peak of $250 \mathrm{mg} / \mathrm{dl}$ after $15 \mathrm{~h}$ ). After the second betamethasone injection, intravenous insulin was introduced reducing the degree and duration of hyperglycaemic peaks $(<200 \mathrm{mg} / \mathrm{dl})$.

Fig. 1E shows the graph of the first patient in which intravenous insulin was introduced after the first betamethasone dose resulting in an acceptable level of glycaemia from the beginning and for all two days of treatment.

We wish to stress the importance of reducing glycaemia and keeping blood glucose under tight control during administration of betamethasone not only for the metabolic status of the mother but to avoid hyperinsulinism of fetus that block the beneficial effect of betamethasone on pulmonary maturation.

No newborn from mothers of our study developed Respiratory Distress Syndrome after the birth.

Another period of high risk for babies from type 1 diabetic mothers is during delivery, when hyperglycaemia could induce the newborns to produce high amounts of insulin with the consequence of hypoglycaemic status after the cut of the blood cord.

The profile in Figure 1A, obtained with a continuous glucose monitoring system (CGMS ${ }^{\oplus}$; Medtronic USA) not equipped for real-time visualization of the results, shows that rapid, prolonged hyperglycaemia can occur during labor and has provided opportunities to examine limitations of conventional monitoring of glycaemia by intermittent finger-stick testing.

Figure $1 \mathrm{~B}$ and $1 \mathrm{C}$ (vaginal delivery and caesarean section) obtained with a Guardian ${ }^{\circledast}$ Real Time CGMS (Medtronic) equipped for real-time visualization of the results shows that the continuous infusion of insulin (between $0.02 \mathrm{U} /$ $\mathrm{kg} / \mathrm{h}$ and $0.06 \mathrm{U} / \mathrm{kg} / \mathrm{h}$ ), guided by glucose levels, enabled us to reach and maintain glucose levels constant between 100 and $150 \mathrm{mg} / \mathrm{dl}$ during labor up to the vaginal delivery and between 80 and $100 \mathrm{mg} / \mathrm{dl}$ during the caesarean section birth.
The mean glycemic values of infants immediately after birth was $84 \pm 16 \mathrm{mg} / \mathrm{dl}$ and no hypoglycaemic episode was recorded during the first $72 \mathrm{hrs}$ after birth.

\section{Conclusion}

Real-time CGMS is a very useful tool for obstetrics and diabetologists during the follow up of the pregnant type 1 diabetic patients in particular when the objective of the therapy is euglycaemia. The sensor is useful because it permits a closer observation of the fluctuation of blood glucose levels. It would be impossible to measure blood glucose on capillary blood at the same frequency intervals mainly for the discomfort of the repeated punctures.

Therefore, we wish to stress the importance of reducing glycaemia during administration of betamethasone and during the labor. It is conceivable that the scarce attention paid to monitoring glucose levels in diabetic mothers during labour in gynaecological worlds may be due to the difficulty in glucose monitoring with the traditional devices until now available. Hopefully, our anecdotal account may prompt improvements in CGMS, and may lead to a better approach to the problem, thereby changing the prognosis of infants born to diabetic mothers.

\section{Competing interests}

The authors declare that they have no competing interests.

\section{Authors' contributions}

DI conceived the study, and participated in its design and coordination. FS participated in the study design and coordination. GS participated in the design of the study and performed the analysis of the results. GV participated in the design of the study. PP have made substantial contributions to acquisition of data. GP have been involved in drafting the manuscript and revising it critically for important intellectual content. FP conceived the study, and participated in its design and interpretation of data. All Authors read and approved the final manuscript.

\section{Acknowledgements}

We thank all the mothers with diabetes who collaborated in the study, Irene lannitti for her collaboration and constructive comments, and Jean Ann Gilder for text editing.

\section{References}

I. Barnes-Powell LL: Infants of diabetic mothers: the effects of hyperglycemia on the fetus and neonate. Neonatal Netw 2007, 26(5):283-90.

2. Schumacher A, Sidor J, Bühling KJ: Continuous glucose monitoring using the glucose sensor CGMS in metabolically normal pregnant women during betamethasone therapy for fetal respiratory distress syndrome. Z Geburtshilfe Neonatol 2006, 2 I 0(5): 184-90.

3. Nold M, Georgieff M: Infants of diabetic mothers. Pediatric Clinics of North America 2007, 5 I :619-637.

4. Schumacher A, Sidor J, Bühling KJ: Continuous glucose monitoring using the glucose sensor CGMS in metabolically normal pregnant women during betamethasone therapy for fetal 
respiratory distress syndrome. Z Geburtshilfe Neonatol 2006, 2 I0(5): 184-90.

5. McLachlan K, Jenkins A, O'Neal D: The role of continuous glucose monitoring in clinical decision-making in diabetes in pregnancy. Aust N Z J Obstet Gynaecol 2007, 47(3): 186-90.

6. Kerssen A, de Valk HW, Visser GH: The Continuous Glucose Monitoring System during pregnancy of women with type I diabetes mellitus: accuracy assessment. Diabetes Technol Ther 2004, 6(5):645-5I.

\section{Pre-publication history}

The pre-publication history for this paper can be accessed here:

http://www.biomedcentral.com/1471-2393/8/23/prepub

Publish with Bio Med Central and every scientist can read your work free of charge

"BioMed Central will be the most significant development for disseminating the results of biomedical research in our lifetime."

Sir Paul Nurse, Cancer Research UK

Your research papers will be:

- available free of charge to the entire biomedical community

- peer reviewed and published immediately upon acceptance

- cited in PubMed and archived on PubMed Central

- yours - you keep the copyright

Submit your manuscript here:

http://www.biomedcentral.com/info/publishing_adv.asp 